\title{
25. EOCENE TO PALEOCENE MICROFOSSIL OF UNKNOWN AFFINITY
}

\author{
Katharina Perch-Nielsen, Institute of Historical Geology and Palaeontology, Copenhagen K, Denmark ${ }^{1}$
}

At Sites 280 and 283 of DSDP Leg 29, a microfossil of unknown affinities was found in sediments of late mid Eocene and late Eocene to late Paleocene age, respectively. Both sites were drilled in deep water: in 4186 meters at Site 280 southwest of Tasmania and in 4729 meters at Site 283 in the Tasman Sea. Deposition of the sediments in which the microfossils were found was thought to have occurred at depths below or near the calcite compensation depth.

Other microfossils present in Sample 280A-22, CC include only palynomorphs, with calcareous and siliceous microfossils being absent. In the samples from Site 283, where the microfossil in question has been found, palynomorphs occur together with arenaceous foraminifera and sometimes very rare diatoms and radiolarians. The microfossil was not found at Sites 277 and 282 in the Eocene or Paleocene calcareous sediments.

'Present address: Department of Geology, Swiss Federal Institute of Technology, Zurich, Switzerland.
The shape of the microfossil varies from wormlike to cone and glass-shaped. The size is from a few microns, to about 150 microns. It consists of a yellow-brownish wall built up by rings surrounding a central canal. The chemical composition of the wall has not accurately been determined, but is known not to be siliceous or calcareous. The fossil does not survive the sample treatment given for palynological studies of the sediment.

While very large forms were often found as loose, single forms, the smaller ones tend to be attached to a quartz grain, or another substratum (including an arenaceous foraminifer at Site 283). Several colonybuilding cones were observed and are illustrated together with single cones on Plates 1 and 2. Some cones were found having grown on an amphore-shaped body. It seems, that the organism secreting these cones was living attached to hard objects.

It was not found in any other than the lowermost sample above the basalt at Site 280. This leads to a conclusion that it formed as part of a benthonic fauna/flora living at or near basement before the deposition of abundant detritus. At Site 283 it occurs in a silty claystone where bioturbation indicates the former presence of other benthos. 
PLATE 1
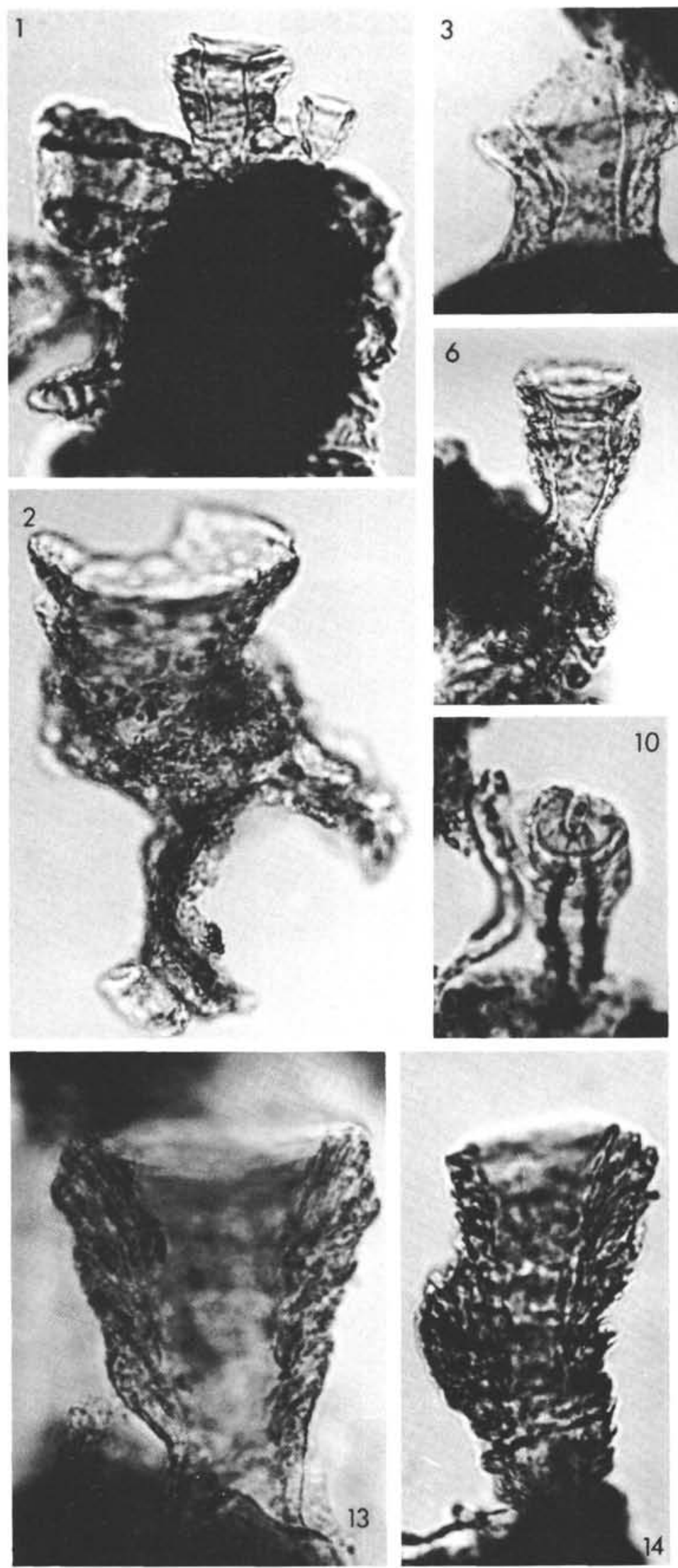

4
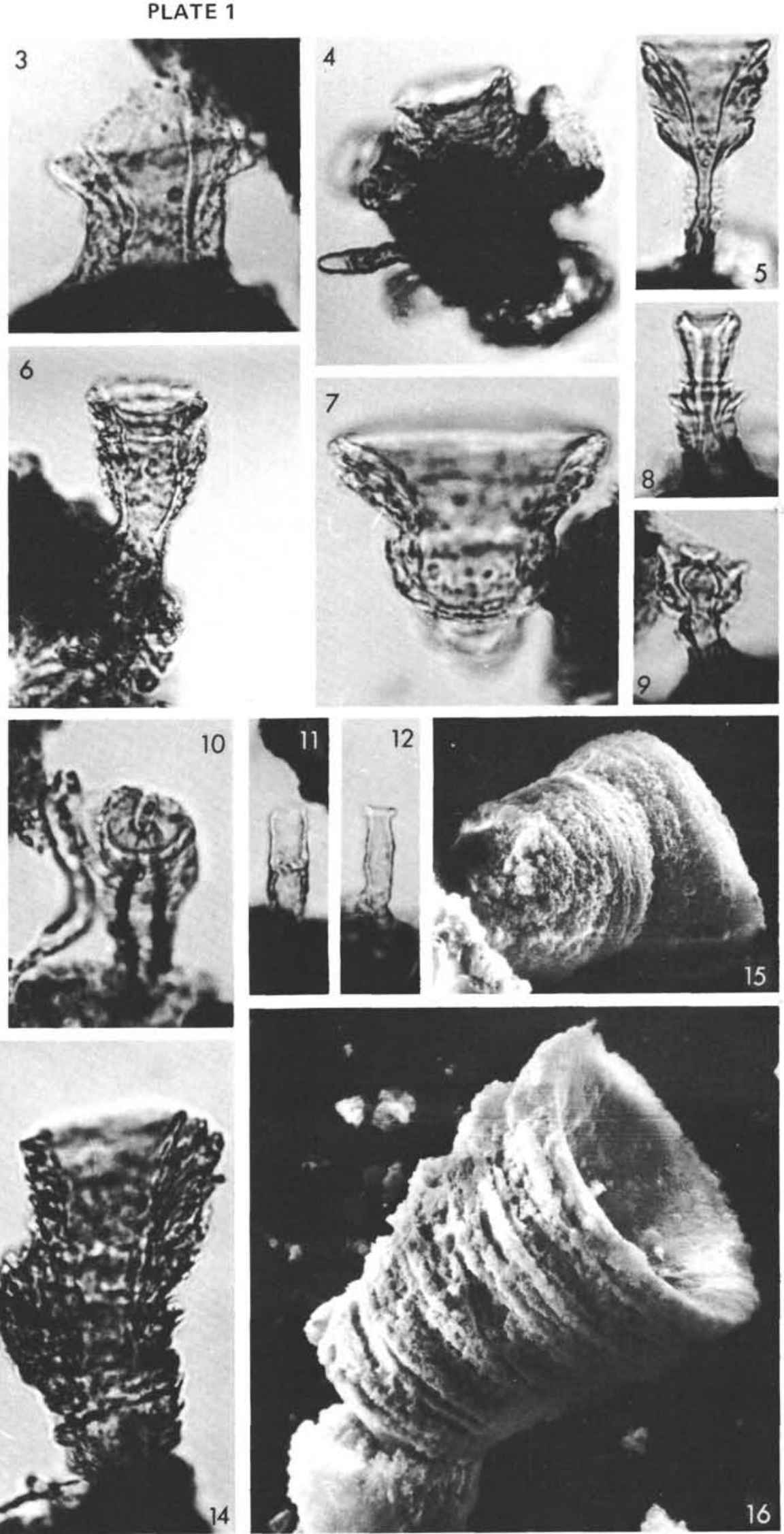

16

Microfossil of unknown affinity from DSDP 29-280A-22, CC.

Figures 1-14 Light microscope pictures of specimens mounted in Canada balsam; magnification $\sim 800 \times$.

Figures 15, 16 Scanning electron microscope pictures of cones broken off from their substratum; magnification $\sim 1900 \times$. 
PLATE 2
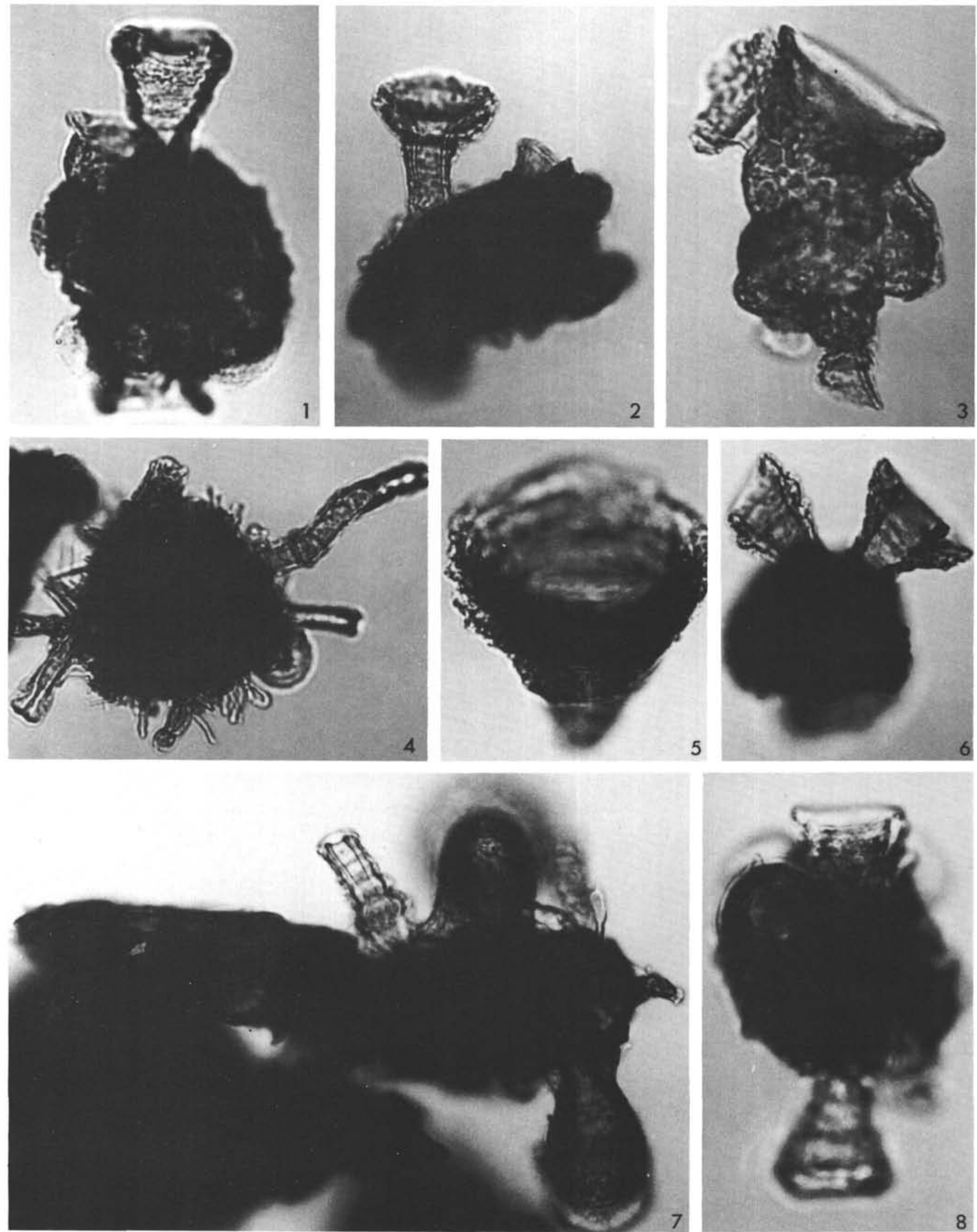

Microfossil of unknown affinity from DSDP 29-280A-22, CC.

Light microscope pictures of specimens mounted in Canada balsam; magnification $\sim 800 \times$ 